\title{
Experimental test on the use of MS-222 for ostracod anaesthesia: concentration, immersion period and recovery time
}

\author{
Olivier SCHMIT* and Francesc MEZQUITA \\ University of Valencia, Dept of Microbiology \& Ecology, Av. Dr Moliner 50, 46100 Burjassot, Spain \\ *e-mail corresponding author: olivier.schmit@uv.es
}

\begin{abstract}
Anaesthesia of animals may be useful for different purposes, particularly for veterinary reasons or in experimental research, for manipulation or treatment of immobilized but alive animals. Its use in crustaceans is not uncommon, but it has never been described for Ostracoda. We provide brief and preliminary guidelines on the use of the tricaine mesylate (MS-222) on the widespread freshwater ostracod Eucypris virens and we show that this compound is an effective anaesthetic used as a bath treatment at minimum concentrations of $500 \mathrm{mg} \mathrm{L}^{-1}$. This value is considerably higher than that recommended for other aquatic animals like fish. Recovery time, ranging from 5 to 15 minutes, is mostly determined by anaesthetic bath concentration, while bath duration influenced to a lesser extent. Anaesthesia induced with MS-222 can prove useful for minute manipulation of living ostracods e.g. for identification, marking or image capture under the microscope.
\end{abstract}

Key words: Eucypris virens, Crustacea, tricaine mesylate, sedation, surgery, marking

\section{INTRODUCTION}

Manipulation of small-bodied invertebrates is delicate per se. When detailed observations are necessary, the observer normally uses needles and thin paintbrushes under a stereomicroscope to place the specimen in a suitable position. Movements of living animals render these observations very difficult or even impossible. However, for experimental purposes, one may want to manipulate immobile but living animals, e.g. for identification, photography, marking, surgery, observation of appendages or inner tissues prior to further experimental use. In such cases, anaesthesia is necessary. Fish are the aquatic animals for which the largest body of knowledge on anaesthesia is available (Ross \& Ross 1999; Ortuño et al. 2002). Some chemicals are also known to be active on macrocrustaceans (Brown et al. 1996; Hajek et al. 2009), but less is known about anaesthesia of microcrustaceans. The use of anaesthetics is common for large crustaceans in aquaculture, e.g. for transport or manipulation, but anecdotic for small-bodied species like amphipods (Ahmad 1969; Gamble 1969; Venarsky \& Wilhelm 2006).

MS-222 (also known as tricaine methanesulfonate or ethyl 3-aminobenzoate methanesulfonic acid) is a drug commonly used in veterinary practice for anaesthesia or euthanasia of a wide variety of animals (Ross \& Ross 1999, AVMA 2007). However, the sensitivity to MS222 is species-specific and highly variable, thus requiring careful optimization of working doses. Concentrations higher than $250 \mathrm{mg} \mathrm{L}^{-1}$ are lethal for fish and are used for euthanasia (AVMA 2007). In amphibians on the other hand, $500 \mathrm{mg} \mathrm{L}^{-1}$ baths only result in anaesthesia (Cecala et al. 2007). Moreover, a dose of $1000 \mathrm{mg}$
$\mathrm{L}^{-1}$ has been shown to have a relaxant effect on a marine gastropod species (Acosta-Salmón \& Davis 2007). To our knowledge, the use of anaesthetics has never been reported in ostracods. Here, we determine effective concentrations of MS-222 for the anaesthesia of Eucypris virens in bath treatment, and the effects related to the duration of the latter, with the aim of allowing safe manipulation of immobilised animals.

\section{METHODS}

Eucypris virens is a freshwater ostracod (small benthic crustacean) common in Palearctic temporary ponds (Meisch 2000). Experimental individuals were sampled on November $29^{\text {th }} 2008$ from a population present in a temporary pond $\left(30 \times 15 \mathrm{~m}\right.$ wide, $Z_{\max }=60 \mathrm{~cm}$, $\mathrm{T}^{\mathrm{o}}=17.5^{\circ} \mathrm{C}, \mathrm{pH}=7.8, \mathrm{EC}=1.34 \mathrm{mS} \mathrm{cm}^{-1}, \mathrm{Alk}=4.9$ mmol L $\left.{ }^{-1},\left[\mathrm{Cl}^{-}\right]=270 \mathrm{mg} \mathrm{L}^{-1}\right)$ in an interdunal wetland south of Valencia, Spain $\left(39^{\circ} 19^{\prime} 28^{\prime \prime} \mathrm{N} 0^{\circ} 18^{\prime} 18^{\prime \prime} \mathrm{W}\right)$. The ostracods were transported to the lab, where they were acclimatized in the original water from the pond at room temperature $\left(\mathrm{ca} 20^{\circ} \mathrm{C}\right)$ for two days before the experiment. Following Schmit et al. (2007), dry Spirulina was added as a food supply to the living algae and vegetal detritus from the original pond. Anaesthesia was prepared by dissolving 98\% pure MS-222 salt (SigmaAldrich) in field water. Preliminary tryouts showed that low concentrations (ranging from 5 to $100 \mathrm{mg} \mathrm{L}^{-1}$ ), similar to those used for fish anaesthesia, were inefficient, even after hours of immersion. Higher MS-222 concentrations $\left(500,1000\right.$ and $\left.2000 \mathrm{mg} \mathrm{L}^{-1}\right)$ were therefore used. In each bath, the ostracods were kept for four different durations: 2, 10, 15 and $30 \mathrm{~min}$. A total of 48 individuals - adult females - were used, with a balanced design (4 individuals per treatment). After immersion in 


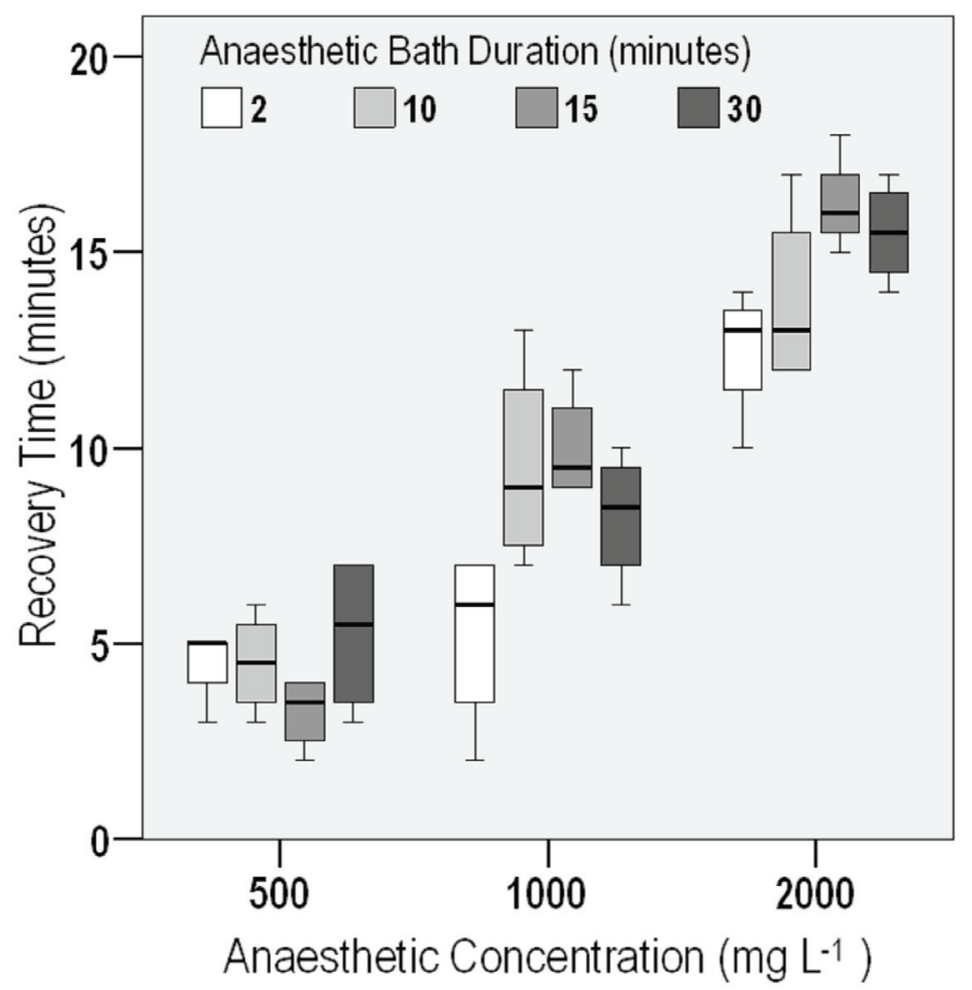

Fig. 1. BoxPlot of recovery time in E. virens individuals subjected to three MS-222 concentrations and four bath durations. Boxes show the first and third quartiles, whiskers the minimum and maximum, and the horizontal line is the median.

the anaesthetic bath, the ostracods were immediately put back in their original untreated field water. For each individual, we recorded the time until the first movements were observed - i.e. the recovery time. The results were statistically treated with a two-way analysis of variance (ANOVA) using the MS-222 concentration and the duration of the anaesthetic bath as independent factors and the recovery time as dependent variable.

\section{RESULTS AND DISCUSSION}

The induction time - i.e. elapsed from immersion of the ostracods in the bath until they stopped moving depended on the concentration of the anaesthetic: in the 500,1000 and $2000 \mathrm{mg} \mathrm{L}^{-1}$ baths it was ca $2.5 \mathrm{~min}, 40 \mathrm{~s}$ and $20 \mathrm{~s}$ respectively. The main determinant of ostracod recovery time was the anaesthetic bath MS-222 concentration: as expected, ostracods took longer to recover when treated with higher concentrations (Fig. 1; ANOVA: $\mathrm{F}=134.8, p<0.001)$. Bath duration also influenced recovery speed: the longer the bath the slower the recovery (ANOVA: $\mathrm{F}=4.8, p=0.007$ ). However, this was not the case at low MS-222 concentration $\left(500 \mathrm{mg} \mathrm{L}^{-1}\right.$; ANOVA interaction effect: $\mathrm{F}=2.8$, $p=0.023)$. Furthermore, at concentrations of 1000 and $2000 \mathrm{mg} \mathrm{L}^{-1}$, the bath duration did not have much effect when above 15 min (Fig. 1).

Under the stereomicroscope, we observed that individuals immersed in a bath with a concentration of 500 mg $\mathrm{L}^{-1}$ of MS-222 showed spasmodic movements of some appendages. At $1000 \mathrm{mg} \mathrm{L}^{-1}$, such movements almost disappeared and were restricted to the vibratory plates (branchial organs on the maxillula). At $2000 \mathrm{mg}$ $\mathrm{L}^{-1}$ no soft parts movements could be observed even inside the body in transmitted light. In all cases, the ostracods laid on the bottom of the Petri dish with the valves opened, allowing easy observation of the soft parts. All individuals behaved normally after recovery (normal swimming, eating and defecating activities) and none of them died in the following days.

For ostracod anaesthesia with MS-222, we recommend to use a minimum concentration of $500 \mathrm{mg} \mathrm{L}^{-1}$. At this concentration, ostracods can be kept for a long time in the anaesthetic bath (with no effect on recovery time) allowing for a long lasting manipulation. If absence of anaesthetic in the medium is preferred, the operation or experiment can be conducted during the recovery phase. This phase can be prolonged up to 10 or 15 min using higher MS-222 concentrations and longer immersion in the anaesthetic bath prior to manipulation.

The concentrations used here are much higher ( $c a 10$ times) than those necessary for fish (Ross \& Ross 1999; Ortuño et al. 2002) but lower than those used with macrocrustaceans. A concentration of $1000 \mathrm{mg} \mathrm{L}^{-1}$ neither affects the crayfish (Brown et al. 1996) nor the Chinese mitten crab (Hajek et al. 2009). The dose to be applied on ostracods is similar to the $500 \mathrm{mg} \mathrm{L}^{-1}$ used with amphipods by Gamble (1969) and Ahmad (1969). 
Although we only tested one ostracod species, E. virens, these similarities in active concentrations suggest that our results may be generalised to other ostracod species.

Other chemicals are also known to be effective anaesthetics of microcrustaceans (Robinson et al. 1965; Gannon \& Gannon 1975; McKenzie et al. 1992). Especially clove oil (Venarsky \& Wilhelm 2006) seems to give good results. However, here we present the first data on ostracod anaesthesia using MS-222 with positive results.

\section{ACKNOWLEDGEMENTS}

We thank Jochen Vandekerkhove, Giampaolo Rossetti and an anonymous referee for their helpful suggestions on the manuscript. Marie Manandise and Benoit H. Dessailly (Univ. Coll. London) kindly corrected the English. This work was funded by the EU Marie Curie Research Training Network SEXASEX (From Sex to Asex: a case study on interactions between sexual and asexual reproduction, contract MRTN-CT-2004512492). This work was also partially funded by the Spanish Ministry of Science and Innovation project ECOINVADER (CGL2008-01296/BOS).

\section{REFERENCES}

Acosta-Salmón, H. \& M. Davis. 2007. Inducing relaxation in the queen conch Strombus gigas (L.) for cultured pearl production. Aquaculture, 262: 73-77.

Ahmad, M. F. 1969. Anaesthetic effects of tricane methane sulphonate (MS 222 Sandoz) on Gammarus pulex (L.) (Amphipoda). Crustaceana, 16: 197-201.

AVMA Guidelines on Euthanasia (Formerly, 2000 Report of the AVMA Panel on Euthanasia), June 2007. http://www. avma.org/resources/euthanasia.pdf.
Brown, M.R. White, J. Chaille, M. Russell \& C. Oseto. 1996. Evaluation of three anesthetic agents for crayfish (Orconectes virilis). J. Shellfish Res., 15(2): 433-435.

Cecala, K.K., S.J. Price \& M.E. Dorcas. 2007. A comparison of the effectiveness of recommended doses of MS-222 (tricaine methanesulfonate) and Orajel ${ }^{\mathbb{R}}$ (benzocaine) for amphibian anesthesia. Herpetol. Rev., 38(1): 63-66.

Gamble, J.C. 1969. An anaesthetic for Corophium volutator (Pallas) and Marinogammarus obtusatus (Dahl), Crustacea, Amphipoda. Cell. Mol. Life Sci., 25(5): 539-540.

Gannon, J.E \& S.A. Gannon. 1975. Observations on the narcotization of crustacean zooplankton. Crustaceana, 28(2): 220-224.

Hajek, G., M. Choczewski, R. Dziaman \& B. Kłyszejko. 2009. Evaluation of immobilizing methods for the chinese mitten crab, Eriocheir sinensis (Milne-Edwards). EJPAU, 12(2), \#18.

McKenzie, J.D., P. Calow, J. Clyde, A. Miles, R. Dickinson, W.R. Lieb \& N.P. Franks. 1992. Effects of temperature on the anesthetic potency of halothane, enflurane and ethanol in Daphnia magna (Cladocera, Crustacea). Comp. Pharmacol. Toxicol., 101(1): 15-19.

Meisch, C. 2000. Freshwater Ostracoda of Western and Central Europe. Spektrum Akademischer Verlag, Gustav Fischer, Heidelberg, Berlin: 522 pp.

Ortuño, J., M.A. Esteban \& J. Meseguer. 2002. Effect of four anaesthetics on the innate immune response of gilthead seabream (Sparus aurata L.). Fish Shellfish Immunol., 12: 49-59.

Robinson, A.B., K.F. Manly, M.P. Anthony, J.F. Catchpool \& L. Pauling. 1965. Anesthesia of Artemia larvae: Method for quantitative study. Science, 149: 1255-1258.

Ross, L.G. \& B. Ross. 1999. Anaesthetic and Sedative Techniques for Aquatic Animals. Blackwell Science, Oxford: $176 \mathrm{pp}$.

Schmit, O., G. Rossetti, J. Vandekerkhove \& F. Mezquita. 2007. Food selection in Eucypris virens (Crustacea: Ostracoda) under experimental conditions. Hydrobiologia, 585: 135-140.

Venarsky, M.P. \& F.M. Wilhelm. 2006. Use of clove oil to anaesthetize freshwater amphipods. Hydrobiologia, 568: 425-432. 